УДК 34

\title{
ПРАВОВАЯ МОДЕЛЬ МЕДИАТИВНЫХ СОГЛАШЕНИЙ
}

\author{
Обухова Любовь Александровна \\ магистрант \\ ФГАОУ ВО "Самарский Государственный Экономический Университет" \\ Научный руководитель: Чугурова Татьяна Викторовна
} к.П.н., доцент

Аннотация: Статья посвящена правовой модели медиативных соглашений в российском и международном законодательстве. Рассмотрены основные положения медиативных соглашений в гражданских правоотношениях. Кроме того, в статье раскрываются явное отличие медиативных соглашений от известных и распространенных мировых соглашений.

Ключевые слова: досудебное урегулирование спора, медиативное соглашение, медиатор, правовая модель.

\section{LEGAL MODEL OF MEDIATION AGREEMENTS}

\section{Obukhova Lyubov Aleksandrovna Scientific adviser: Chugunova Tatyana Viktorovna}

\begin{abstract}
The article is devoted to the legal model of mediation agreements in Russian and international legislation. The main provisions of mediation agreements in civil legal relations are considered. In addition, the article reveals the obvious difference between mediation agreements and well-known and common settlement agreements.
\end{abstract}

Key words: pretrial settlement of the dispute, a mediation agreement, mediator, legal model.

На данный момент медиация, хоть и известна в мире как один из возможных способов урегулирования возникающих споров, но на практике свое применение и результативность не часто демонстрирует. Одной из причин этого фактора является недоверие со стороны населения, в силу того, что у 


\section{НАУКА, ОБЩЕСТВО, КУЛЬТУРА: ПРОБЛЕМЫ И ПЕРСПЕКТИВЫ ВЗАИМОДЕЙСТВИЯ В СОВРЕМЕННОМ МИРЕ}

данной процедуре нет силы власти, как у тех же самых судебных решений. Можно говорить о том, что развитие альтернативного урегулирования споров представляет собой одно из глобальных направлений совершенствования гражданского процесса, который будет являться составной частью комплекса реформ, направленных на модернизацию и ускорение правосудия. Российская Федерация как прогрессирующая и развивающаяся страна не отстает от мирового течения юридической науки и практики, анализирую как своей собственный опыт, так и опыт зарубежных стран. Весьма актуальным на сегодня остается вопрос о модернизации внедрения примирительных процедур в российское право. Соответственно вступивший в силу в Российской Федерации Закон «Об альтернативной процедуре урегулирования споров с участием посредника (закон о процедуре медиации)», создал правовые основания для становления и развития правовой модели и как следствие института медиации в России.

Статья 12 Федерального закона «Об альтернативной процедуре урегулирования споров с участием посредника (процедуре медиации) №19 ЭФ3 от 27 июля 2010 года посвящена медиативному соглашению. Касательно правовой природы медиативного соглашения в юридической среде она вызывает немало разногласий. Некоторые отмечают, что острые споры по данной теме вызывают проблемы сомой сущности и правовой природы, наличия юридической силы соглашений, существования разного рода последствий как заключения, так и исполнения или неисполнения медиативного соглашения. Процедура медиации предполагает урегулирование спора исходя из интересов сторон, а потому медиативное соглашение может выходить за предмет первоначальных требований и зачастую будет лишь косвенным образом связано со спорным правоотношением.

В законе о Медиации четко разграничены несколько видов медиативных соглашений в зависимости от момента их заключения. Так заключение медиативного соглашение возможно как после передачи дела на рассмотрение суд, так и без обращения в суд по рассматриваемому спору. Практической значимостью такой классификации состоит в необходимости разграничения правых последствий.

Есть точка зрения, касающаяся правовой природы медиативного соглашения, которая является более распространенной. Суть ее в следующем: необходимо разграничение медиативного соглашения в рамках частной медиации, тогда решение будет рассматриваться в качестве сделки, что 


\section{НАУКА, ОБЩЕСТВО, КУЛЬТУРА: ПРОБЛЕМЫ И ПЕРСПЕКТИВЫ ВЗАИМОДЕЙСТВИЯ В СОВРЕМЕННОМ МИРЕ}

направлена на установление, изменение или прекращение субъективных прав и обязанностей сторон, и с другой стороны разграничение ее в рамках судебной медиации, по здесь решение приравняется к мировому соглашению.

В процедуре медиации медиативное соглашение, что достигли участники процесса после его передачи в суд, утверждается судом или третейским судом в варианте мирового соглашения с соответствии с процессуальным законодательством. Однако проводить параллель между двумя этими понятиями не стоит, так как они не являются взаимозаменяемыми. Медиативное соглашение может «транспонироваться» в мировое при соблюдении конкретных условий: во-первых, если спор являлся судебным рассмотрением; во-вторых, в качестве мирового соглашение может рассматриваться только медиативное соглашение в форме письменного документа или путь непосредственной фиксации предмета договора и его результата в тексте медиативного соглашении.

Медиативное соглашение по возникшему из гражданских правоотношений спору, достигнутое сторонами, в результате процедуры медиации, проведенной без передачи спора на рассмотрение суда или третейского суда, представляет собой гражданско-правовую сделку, направленную на установление, изменение или прекращение прав и обязанностей сторон. К такому варианту, когда вопрос представляет собой гражданско-правовую сделку, к нему применяются правила гражданского законодательства об отступном, о новации, о прощении долга, о зачете встречного однородного требования, о возмещении вреда. Защита прав, нарушенных в результате медиативного соглашения, осуществляется так же посредством гражданского законодательства.

Медиативное соглашение должно включать: сведения о сторонах, предмете спора, проведенной процедуре медиации, медиаторе, а также согласованные сторонами обязательства, условия и сроки их выполнения.

В российской правовой системе медиатор должен контролировать конечное соглашение, иначе заключенное медиативное соглашение может считаться недействительным.

Процедура медиации направлена на изменение и завершение спорных материально-правовых отношений с помощью заключения медиативного соглашения. Реализация установленных сторонами обязательств значима для исследования правовой природы соглашения. 


\section{НАУКА, ОБЩЕСТВО, КУЛЬТУРА: ПРОБЛЕМЫ И ПЕРСПЕКТИВЫ ВЗАИМОДЕЙСТВИЯ В СОВРЕМЕННОМ МИРЕ}

Что же на самом деле представляет собой медиативное соглашение? Медиативное соглашение - это соглашение, достигнутое участниками спорного вопроса при применении процедуры медиации в целях урегулирования спора и частичных разногласий по спору.

Медиативное соглашение - это результат проведения эффективной процедуры медиации.

Из результатов исследований и правоприменительной практики можно понять, что правовая природа медиативного соглашения значительно шире по возможности своего действия, чем мы думаем на субъективном уровне.

Касательно правовой сущности и природы медиативных соглашений, заключаемых в области трудовых и семейных правоотношений, законодательно не определена. Некоторые деятели рассуждают о допустимости субсидиарного распространения режима гражданско-правовых сделок на медиативные соглашения, заключенные в результате урегулирования спора, возникшего из семейных и трудовых правоотношений.

Основной особенностью медиативного соглашения остается обязательность волеизъявления участников спорного правоотношения в отношении участия в медиативном процессе, зачет обоюдных единых требований признает право одной стороны. Гражданское законодательство содержит пункт о соблюдении условий тождественности зачитываемых требований. Несопоставимость требований сторон в сфере медиации допускает законодательство в сфере медиации.

Так как целью медиативного соглашения во внесудебном и досудебном порядке является урегулирование спора, но на практике она не имеет своей силы как исполнительного документа. Обращение в суд с заинтересованной стороны или же в третейский суд возможно с целью защиты прав и законных интересов, если соглашение было не исполнено или исполнено не надлежаще. А так же возможно и нотариальное удостоверение медиативного соглашения, если стороны при обращении к нотариусу за помощью в урегулировании их вопроса, имея острую необходимость заключения медиативного соглашения, достигли обоюдного результата.

По прошествии нескольких лет можно уловить наметившуюся тенденцию, что эффективность применения на практике законодательства о медиации, совершенствующиеся правовые нормы, в том числе и медиативное соглашение, зависит от модернизации в соответствующем государстве законодательства о медиации. 


\section{НАУКА, ОБЩЕСТВО, КУЛЬТУРА: ПРОБЛЕМЫ И ПЕРСПЕКТИВЫ ВЗАИМОДЕЙСТВИЯ В СОВРЕМЕННОМ МИРЕ}

Конечно всем известный факт, что законодательство о медиации во многих странах еще не совершенно. Но медиативное соглашение, его межотраслевой характер, как и сама медиация, имеют большую перспективу и будут развиваться. Потому что интерес к практической медиации не только по правовым спорам, но и по конфликтам самого разного характера, не приобретшим правового характера, во многих странах различен, но не иссякает. Поэтому стоит в дальнейшем исследовать универсальность и комплексность социального правового явления, как медиативное соглашение.

Подводя итоги правовой сущности медиативного соглашения, нужно указать на значение его сущности, оно в первую очередь состоит в возможности урегулирования вопроса сторон по решению их спора, дальше, не стоит забывать и о реализации обязательств самих сторон. Так же правовая природа медиативных соглашений касается не только решения спорных моментов процессуального права, но и гражданско-правовой природы и, конечно же, касающиеся трудовой и семейной медиации, ведь спорные моменты и конфликты, требующие урегулирования с помощью медиатора, возникают и в обычной не процессуальной действительности.

В свою очередь, возможно, для успешного развития медиации в Российской Федерации, стоит придать медиативному соглашению не просто гражданского акта, а акта итогового. Который будет иметь силу принудительного исполнения посредством закрепления в АПК РФ, для полной уверенности в законности решения медиативного соглашения.

Исполнение принятого соглашения основывается на дифференциации его порядка, в силу различии требований, мирового соглашения, так как зависимость его совершения идет от передачи на рассмотрение в суд.

Конечно, не стоит упускать и тот факт, что востребованность примирительных процедур, а именно и число дел, что рассмотрены с применением процедуры медиации, все еще находятся на низком уровне. Для дальнейшего развития, и, следовательно, увеличения интереса к урегулированию споров посредством применением процедуры медиации, необходимо определить наиболее перспективные тенденции по модернизации данного процесса, затрагивая и усовершенствование медиативного соглашения, опираясь на уровень развития жизни и способности понять все тонкости такой системы урегулирования споров, как медиация. 


\section{Список литературы}

1. Федеральный закон Российской Федерации «Об альтернативной процедуре урегулирования споров с участием посредника (процедуре медиации)» от 27 июля 2010 г. № 193-ФЗ. //С3 РФ.-2010. — № 31. - Ст. 4162.

2. Альтернативное разрешение споров: учебник / Под ред. Е.А. Борисовой. М.: Издательский Дом «Городец», 2019.-.416с.

3. Давыденко Д.Л. Медиативное соглашение. / Д.Л. Давыденко / Медиация: учебник / Под ред. А.Д. Карпенко, А.Д.Осиновского. - СПб: АНО «Редакция журнала «Третьрейский суд»; М.: Статус, 2016.-425-431 с. 